\title{
A Simple Ocean Data Assimilation Analysis of the Global Upper Ocean 1950-95. Part II: Results
}

\author{
James A. Carton, Gennady Chepurin, and Xianhe Cao \\ Department of Meteorology, University of Maryland at College Park, College Park, Maryland
}

(Manuscript received 6 February 1998, in final form 10 February 1999)

ABSTRACT

\begin{abstract}
The authors explore the accuracy of a comprehensive 46-year retrospective analysis of upper-ocean temperature, salinity, and currents. The Simple Ocean Data Assimilation (SODA) analysis is global, spanning the latitude range $62^{\circ} \mathrm{S}-62^{\circ} \mathrm{N}$. The SODA analysis has been constructed using optimal interpolation data assimilation combining numerical model forecasts with temperature and salinity profiles (MBT, XBT, CTD, and station), sea surface temperature, and altimeter sea level. To determine the accuracy of the analysis, the authors present a series of comparisons to independent observations at interannual and longer timescales and examine the structure of well-known climate features such as the annual cycle, El Niño, and the Pacific-North American (PNA) anomaly pattern.

A comparison to tide-gauge time series records shows that $25 \%-35 \%$ of the variance is explained by the analysis. Part of the variance that is not explained is due to unresolved mesoscale phenomena. Another part is due to errors in the rate of water mass formation and errors in salinity estimates. Comparisons are presented to altimeter sea level, WOCE global hydrographic sections, and to moored and surface drifter velocity. The results of these comparisons are quite encouraging. The differences are largest in the eddy production regions of the western boundary currents and the Antarctic Circumpolar Current. The differences are generally smaller in the Tropics, although the major equatorial currents are too broad and weak.

The strongest basin-scale signal at interannual periods is associated with El Niño. Examination of the zerolag correlation of global heat content shows the eastern and western tropical Pacific to be out of phase (correlation -0.4 to -0.6 ). The eastern Indian Ocean is in phase with the western Pacific and thus is out of phase with the eastern Pacific. The North Pacific has a weak positive correlation with the eastern equatorial Pacific. Correlations between eastern Pacific heat content and Atlantic heat content at interannual periods are modest. At longer decadal periods the PNA wind pattern leads to broad patterns of correlation in heat content variability. Increases in heat content in the central North Pacific are associated with decreases in heat content in the subtropical Pacific and increases in the western tropical Pacific. Atlantic heat content is positively correlated with the central North Pacific.
\end{abstract}

\section{Introduction}

Recently we have reported a new retrospective analysis of upper-ocean temperature, salinity, sea level, and currents for the global ocean, 1950-1995 (Carton et al. 2000). The result of that research has been to provide a synthesis of the historical oceanographic data record in the form of a retrospective analysis. Here we describe the results of an exploration of the accuracy of this analysis.

The Simple Ocean Data Assimilation (SODA) algorithm used to construct our retrospective analysis consists of a numerical forecast model and an update procedure to provide corrections to the forecast. The update

Corresponding author address: Dr. James A. Carton, Department of Meteorology, University of Maryland at College Park, 2417 Computer and Space Science Building, College Park, MD 20742-2425. E-mail: carton@metosrv2.umd.edu procedure is based on a data assimilation algorithm widely applied in atmospheric numerical weather prediction called optimal interpolation (see Daley 1991). In optimal interpolation the differences between observed variables such as temperature, salinity, and sea level and model forecasts of the same variables are used to update the forecast. The interpolation coefficients, otherwise known as gain matrices, are determined so as to minimize the mean square error of the analysis. Our implementation of this algorithm differs from the usual implementation to the extent that we include spatial dependence of the assumed error statistics and because of our assumptions about bias in the model forecast.

SODA differs from the more sophisticated but much more computationally intensive Kalman filter to the extent that we do not have prediction equations for the temporal and spatial evolution of the error statistics. Rather, the error statistics are determined a priori based on a statistical analysis of errors from a preliminary analysis. Our approach also bears similarity to 3D var- 
TABLE 1. Ocean analysis experiments presented in the text. Each experiment covers the period 1950-96. Further description of these experiments is provided in Carton et al. (2000).

\begin{tabular}{ll}
\hline \hline \multicolumn{1}{c}{ Experiment } & \multicolumn{1}{c}{ Description } \\
\hline $\begin{array}{l}\text { Control analysis } \\
1\end{array}$ & $\begin{array}{l}\text { Basic analysis with detrended winds } \\
\text { Basic analysis except assuming significant fore- } \\
\text { cast error bias }\end{array}$ \\
2 & Simulation with no subsurface updating \\
3 & Basic analysis with climatological monthly winds \\
4 & Basic analysis with complete winds \\
5 & Basic analysis except with salinity updating with \\
& observed salinity, but without $T / S$ error covari- \\
6 & ance \\
7 & Basic analysis except without $T / S$ error covari- \\
& ance \\
8 & Basic analysis except replacing model with cli- \\
& mate temperature \\
& Basic analysis except that TOPEX/Poseidon al- \\
& timeter sea level is excluded from updating \\
& procedure \\
\hline
\end{tabular}

iational assimilation methods when the mean square error is minimized such as that described in Ji et al. (1995). Comparison of the results shows correlations of heat content exceeding 80\% in the tropical Pacific (Chepurin and Carton 1999). Bennett (1990) and Wunsch (1996) provide comprehensive discussions of the alternatives in formulating updating algorithms. Malonote-Rizzoli (1996) reviews many current implementations.

The general circulation ocean model on which our analysis is based uses the full Geophysical Fluid Dynamics Laboratory Modular Ocean Model 2.b primitive equation code, with conventional choices for mixing, etc. The domain of this analysis is global, extending from $62^{\circ} \mathrm{S}$ to $62^{\circ} \mathrm{N}$. The model horizontal resolution is $2.5^{\circ} \times 0.5^{\circ}$ in the Tropics, expanding to a uniform $2.5^{\circ}$ $\times 1.5^{\circ}$ resolution at midlatitude. No attempt is made to resolve midlatitude eddy processes. At the polar boundaries the temperature and salinity fields are relaxed to climatology. We make no attempt to model cryospheric or deep-water formation processes explicitly. A weak 5 -yr relaxation of the global temperature and salinity fields is included in order to reduce forecast bias in deepwater masses. Bottom topography is included. The model has 20 levels in the vertical, with $15-\mathrm{m}$ resolution in the upper $150 \mathrm{~m}$. In this model sea level is obtained through diagnostic calculation from the mass and momentum fields. Winds are provided by an analysis of historical shipboard measurements by da Silva et al. (1994) prior to 1993 and by the National Centers for Environmental Prediction after that date.

The main datasets to constrain the model forecast are the hydrographic data contained in the World Ocean Atlas 1994 (WOA-94; Levitus et al. 1994), additional hydrography obtained from a variety of sources, sea surface temperature (Reynolds and Smith 1994), and altimetry from the Geosat, ERS-1, and TOPEX/Poseidon satellites. The hydrographic dataset exceeds 50000 profiles per year for much of our 46-yr period of interest. This dataset has been collected using several different instruments. In the interval 1950-69, most of the temperature measurements were made with the mechanical bathythermograph. This subset reached a maximum of 70000 measurements per year in 1968, but is limited to sampling temperature in the upper 2-300 m. After 1969 the mechanical bathythermograph was largely re-

TABLE 2. Statistical comparison of control analysis and tide guage sea level for selected stations. Record length is given, along with overall correlation (Cor1) and correlation of 5-yr low-pass filtered records (Cor2). Christmas Island record comes in two parts, each of which has been detrended. The comparison is with the combined record. Correlations marked with an asterisk exceed the $95 \%$ test of significance.

\begin{tabular}{|c|c|c|c|c|}
\hline Name & Location & Years & Cor1 & Cor 2 \\
\hline \multicolumn{5}{|c|}{ Atlantic } \\
\hline San Juan (Puerto Rico) & $18^{\circ} 27^{\prime} \mathrm{N}, 66^{\circ} 05^{\prime} \mathrm{W}$ & 26 & $0.50^{*}$ & 0.34 \\
\hline Tenerife (Canary Is.) & $28^{\circ} 29^{\prime} \mathrm{N}, 16^{\circ} 14^{\prime} \mathrm{W}$ & 38 & -0.02 & -0.21 \\
\hline Bermuda, Is. & $32^{\circ} 22^{\prime} \mathrm{N}, 64^{\circ} 42^{\prime} \mathrm{W}$ & 40 & $0.46^{*}$ & $0.72 *$ \\
\hline La Coruna (Spain) & $43^{\circ} 22^{\prime} \mathrm{N}, 8^{\circ} 24^{\prime} \mathrm{W}$ & 27 & 0.28 & 0.31 \\
\hline \multicolumn{5}{|c|}{ Pacific } \\
\hline Rikitea Is. & $23^{\circ} 8^{\prime} \mathrm{S}, 134^{\circ} 57^{\prime} \mathrm{W}$ & 20 & 0.15 & 0.43 \\
\hline Noumea II & $22^{\circ} 18^{\prime} \mathrm{S}, 166^{\circ} 26^{\prime} \mathrm{E}$ & 22 & $0.52 *$ & $0.77 *$ \\
\hline Pago Pago Is. & $14^{\circ} 17^{\prime} \mathrm{S}, 170^{\circ} 41^{\prime} \mathrm{W}$ & 40 & $0.34 *$ & $0.56^{*}$ \\
\hline Christmas Is. (two parts) & $1^{\circ} 59^{\prime} \mathrm{N}, 157^{\circ} 29^{\prime} \mathrm{W}$ & 14 & $0.86^{*}$ & $0.88 *$ \\
\hline Pahnpei-b Is. & $6^{\circ} 59^{\prime} \mathrm{N}, 158^{\circ} 14^{\prime} \mathrm{E}$ & 17 & $0.86^{*}$ & $0.71 *$ \\
\hline Majuro-b Is. & $7^{\circ} 6^{\prime} \mathrm{N}, 171^{\circ} 22^{\prime} \mathrm{E}$ & 17 & $0.79 *$ & $0.81 *$ \\
\hline Kwajalein Is. & $8^{\circ} 44^{\prime} \mathrm{N}, 167^{\circ} 44^{\prime} \mathrm{E}$ & 45 & $0.73^{*}$ & $0.74 *$ \\
\hline Yap Is. & $9^{\circ} 31^{\prime} \mathrm{N}, 138^{\circ} 8^{\prime} \mathrm{E}$ & 21 & $0.66^{*}$ & $0.91 *$ \\
\hline Guam Is. & $13^{\circ} 26^{\prime} \mathrm{N}, 144^{\circ} 39^{\prime} \mathrm{E}$ & 41 & $0.70 *$ & $0.45^{*}$ \\
\hline Johnston Is. & $16^{\circ} 45^{\prime} \mathrm{N}, 169^{\circ} 31^{\prime} \mathrm{W}$ & 41 & $0.66^{*}$ & $0.40 *$ \\
\hline Wake Is. & $19^{\circ} 17^{\prime} \mathrm{N}, 166^{\circ} 37^{\prime} \mathrm{E}$ & 38 & $0.54 *$ & $0.67 *$ \\
\hline Hilo, Hawaii & $19^{\circ} 44^{\prime} \mathrm{N}, 155^{\circ} 4^{\prime} \mathrm{W}$ & 45 & $0.44 *$ & $0.35 *$ \\
\hline Honolulu, Hawaii & $21^{\circ} 18^{\prime} \mathrm{N}, 157^{\circ} 52^{\prime} \mathrm{W}$ & 45 & $0.67 *$ & $0.70 *$ \\
\hline French Frigate Shoals & $23^{\circ} 52^{\prime} \mathrm{N}, 166^{\circ} 17^{\prime} \mathrm{W}$ & 17 & 0.44 & $0.77 *$ \\
\hline Midway Is. & $28^{\circ} 13^{\prime} \mathrm{N}, 177^{\circ} 22^{\prime} \mathrm{W}$ & 35 & 0.07 & $0.44 *$ \\
\hline Sitka, Alaska & $57^{\circ} 3^{\prime} \mathrm{N}, 135^{\circ} 20^{\prime} \mathrm{W}$ & 35 & 0.07 & $0.44 *$ \\
\hline
\end{tabular}




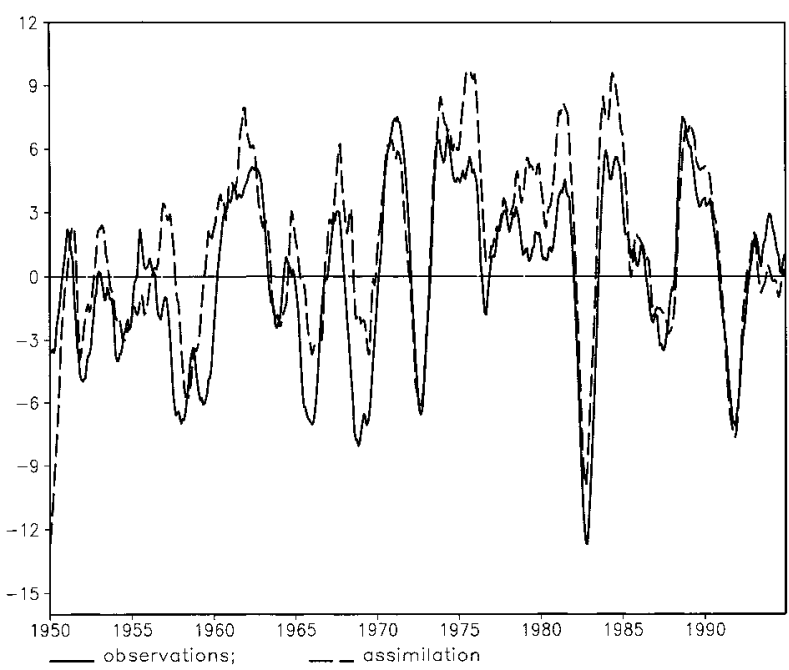

FIG. 1. Observed and control analysis sea level time series at Kwajalein Island $\left(9^{\circ} \mathrm{N}, 168^{\circ} \mathrm{E}\right)$. The seasonal cycle and a linear trend has been removed from both records.

placed by the expendable bathythermograph. Two other small subsets, conductivity-temperature-depth and bottle measurements, are important because they provide salinity as well as temperature and because they extend more deeply into the water column.

The altimeter sea level used here is based on the NASA Pathfinder Project version 2.1 to which we have added all the standard corrections for geophysical effects and then averaged alongtrack into $1^{\circ}$ bins. No other interpolation was carried out. The altimeter dataset begins November 1986 with the Geosat Exact Repeat Mission. No altimeter data is available from the end of Geosat in the fall of 1989 until the beginning of ERS-I in spring 1992.

In addition to the basic analysis, which we refer to as the control analysis, a series of analysis experiments (see Table 1) has been carried out to determine some of the properties and sensitivities of the analysis. The control analysis and analysis experiments begin January 1950 and continue through December 1995. The analysis fields for each experiment consist of 552 monthly averages of temperature, salinity, and the horizontal components of velocity at 20 levels. Comparison of the experiments reveals important sensitivities of the analysis to changes in parameters, boundary conditions, etc. Some review of these results is provided in this paper. A more extensive discussion is provided in Carton et al. (2000).

Here our examination of analysis error focuses on comparison to independent observations on interannual and longer timescales. We limit our comparison to examination of correlations and root-mean-square (rms) differences and a more detailed examination of one example for each dataset. Section 2 examines the temporal variability of the analysis by comparison to tide gauge sea level time series from the Permanent Service for
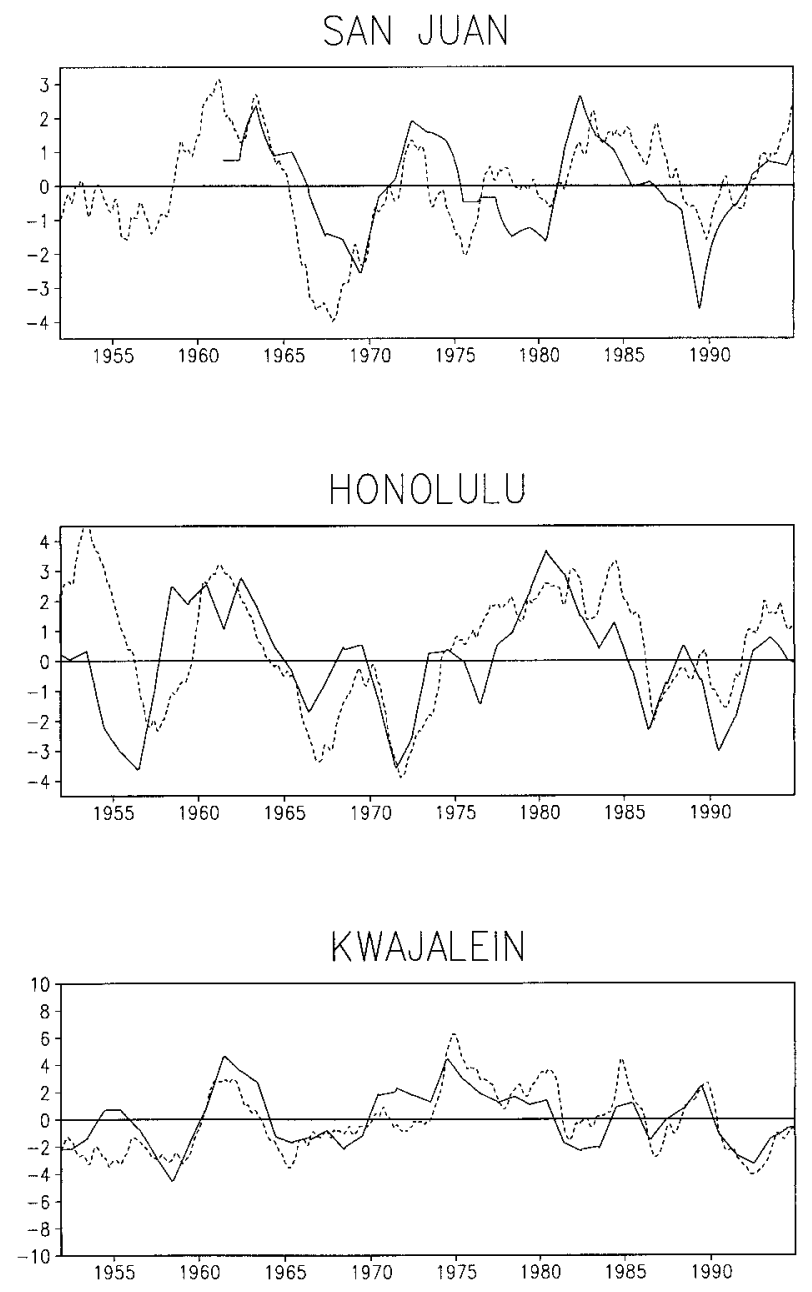

FIG. 2. Five-year low-pass filtered observed and control analysis sea level at three locations: San Juan, Puerto Rico $\left(18^{\circ} \mathrm{N}, 66^{\circ} \mathrm{W}\right)$, Honolulu $\left(21^{\circ} \mathrm{N}, 158^{\circ} \mathrm{W}\right)$, and Kwajalein Island $\left(9^{\circ} \mathrm{N}, 168^{\circ} \mathrm{E}\right)$. A linear trend has been removed from all records. Units are centimeters.

Mean Sea Level. In Section 3 our examination focuses on the spatial structure of analysis error. Datasets with good spatial coverage include altimeter sea level, global hydrographic sections, and surface drifter velocity.

\section{Time series comparisons}

In this section we present a comparison to island tide gauge records. Comparison to temperature and salinity at Bermuda is provided in Carton et al. (2000). Together these datasets allow a detailed examination of the accuracy of the analysis at interannual to decadal periods. The behavior of the analysis at short seasonal periods is also discussed in Carton et al. (2000).

\section{Tide gauge comparison}

Approximately 1800 tide gauge records are available from the Permanent Service for Mean Sea Level or the 

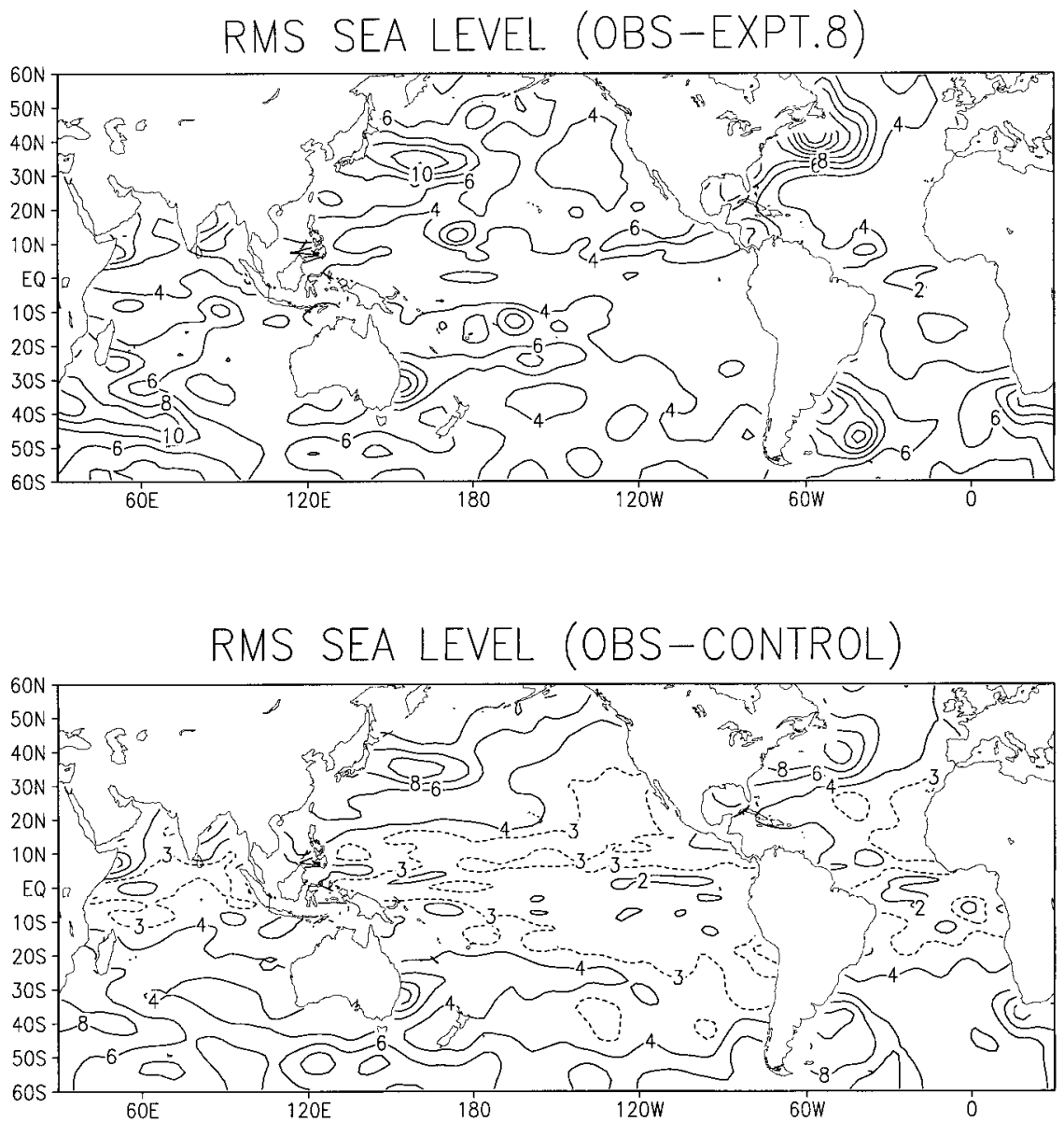

FIG. 3. Sea level error estimated using three years of TOPEX/Poseidon altimetry. (a) Rootmean-square difference between altimeter and expt 8 analysis sea level in which altimeter sea level observations have been excluded from the analysis. (b) Rms difference between altimeter and control analysis sea level in which temperature and salinity are constrained by altimeter observations. Contour intervals are 2 and $1 \mathrm{~cm}$.

Tropical Ocean Global Atmosphere sea level archives. However, many gauges are in locations that are unsuitable for observing the large-scale circulation, while others have records that are too short for our purposes. After examining the datasets we have identified 20 stations, mainly from islands in the North Atlantic and Pacific (in the latitude band $23^{\circ} \mathrm{S}-57^{\circ} \mathrm{N}$ ), with records that each exceed 17 years in length and do not seem excessively gappy or otherwise contaminated.

At each of the station locations we have carried out a comparison between annually averaged observations and control analysis sea-level time series. The comparison is summarized in Table 2. Correlations between observed and control analysis sea level is presented as Cor1. The lowest correlations are for continental stations such as La Coruna, Spain, and for some of the subtropical and midlatitude islands such as the Canary Islands. The agreement at islands in the tropical Pacific such as Kwajalein $\left(9^{\circ} \mathrm{N}, 167^{\circ} \mathrm{E}\right.$ : Fig. 1) is generally excellent. A succession of high and low sea level events in the record at Kwajalein reflects the importance of El Niño throughout the tropical Pacific. The earliest strong event in this record is the El Niño of 1957-58, which is indicated by a rise in sea level followed by a $9-\mathrm{cm}$ drop. The strongest event overall is the 1982-83 El Niño when sea level dropped by $20 \mathrm{~cm}$. The differences between observed and analyzed sea level appear to be of longer than interannual timescale. We examine the decadal behavior of these records below. Interestingly, the anomaly correlations in Table 2 are quite comparable to correlations reported previously by Miller and Cane (1996) for much shorter 2-yr intervals that also included the seasonal cycle.

In order to determine the quality of the comparison at frequencies longer than interannual we next filter all time series with a 5-yr low-pass filter. A linear trend is also removed in order to eliminate unmodeled geophysical effects such as geologic uplift and global sea level rise due to continental ice melt as well as model bias. The resulting gauge comparisons are labeled Cor2 
in Table 2. In two-thirds of the stations in the tropical Pacific the correlation of observed and analysis sea level is improved by low-pass filtering. In mid and high latitude the correlation also improves, but generally remains below 0.5 . The arithmetic average correlation of the two sets of records are 0.48 and 0.56 . If these values are representative they would suggest that the control analysis explains $23 \%$ of the interannual sea level variance, increasing to $31 \%$ on timescales between 5 and 25 years. A significant fraction of the unexplained variance is due to mesoscale processes that cannot be resolved by our analysis and is of less interest to us (the contribution of mesoscale variability is evident in the comparison of the nearby Honolulu and Hilo time series).

The three pairs of low-pass filtered time series shown in Fig. 2 include one (San Juan) that has a correlation of less than 0.5 and two (Honolulu and Kwajalein) that exceed 0.7. At all three stations a visual comparison reveals substantial similarity. The main differences at San Juan seem to be in the specific timing of the anomalies rather than their amplitude or duration. At Honolulu the major differences between observed and analysis sea level occur prior to 1960 , when the subsurface data coverage was less complete.

\section{Additional comparisons}

The comparisons reported in this section involve datasets with more limited temporal coverage but with expanded spatial coverage (altimeter sea level, WOCE hydrography, and drifter and moored currents).

\section{a. Altimeter sea level}

Although the time series comparisons discussed above provide information about interannual to decadal variability, they have limited spatial coverage and have only indirect information about currents. The availability in recent years of satellite altimeter sea level offers us the opportunity to examine the accuracy of the analysis essentially globally. In order to make the comparison to altimeter sea level independent we introduce a new experiment, experiment 8 , in which altimeter sealevel information has been excluded from the updating procedure. We limit our discussion here to consider only the TOPEX/Poseidon altimetry because of its low observation error.

The error in observed monthly averaged TOPEX/Poseidon altimetric sea level has been estimated to be in the neighborhood of $2 \mathrm{~cm}$ in the tropical Pacific (Cheney et al. 1994; Mitchum 1994). The rms difference between observed and experiment 8 sea level exceeds the observation error by $2-4 \mathrm{~cm}$ (Fig. 3a). The difference is lowest in the Tropics and somewhat lower on the eastern side of the basin than on the western side. In the eastern tropical basin the rms difference drops below $3 \mathrm{~cm}$. For
TABLE 3. Rms differences between observed and control analysis temperature and salinity along WOCE hydrographic sections.

\begin{tabular}{|c|c|c|c|}
\hline Name & Location & $\begin{array}{l}\mathrm{Rms}(T) \\
\quad\left({ }^{\circ} \mathrm{C}\right)\end{array}$ & $\begin{array}{c}\mathrm{Rms}(S) \\
(\mathrm{psu})\end{array}$ \\
\hline \multicolumn{4}{|c|}{ Atlantic } \\
\hline $\mathrm{A} 1 \mathrm{E}$ & $52.2^{\circ} \mathrm{N}, 23^{\circ} \mathrm{W}-14^{\circ} \mathrm{W}$ & 0.43 & 0.047 \\
\hline A11 & $44.6^{\circ} \mathrm{S}, 50^{\circ} \mathrm{W}-12^{\circ} \mathrm{W}$ & 1.29 & 0.195 \\
\hline A 16 & $44^{\circ}-59^{\circ} \mathrm{N}, 20^{\circ} \mathrm{W}$ & $0.32 *$ & 0.031 \\
\hline A9 & $19^{\circ} \mathrm{S}, 36^{\circ} \mathrm{W}-13^{\circ} \mathrm{W}$ & $0.36^{*}$ & 0.156 \\
\hline AR4E & $5^{\circ} \mathrm{S}-5^{\circ} \mathrm{N}, 34.5^{\circ} \mathrm{W}$ & 0.93 & 0.138 \\
\hline AR15 & $6^{\circ} \mathrm{S}-2^{\circ} \mathrm{N}, 34.5^{\circ} \mathrm{W}$ & 0.74 & 0.113 \\
\hline \multicolumn{4}{|c|}{ Indian } \\
\hline I5 & $33.5^{\circ} \mathrm{S}, 38^{\circ}-72^{\circ} \mathrm{E}$ & 0.45 & 0.058 \\
\hline \multicolumn{4}{|c|}{ Pacific } \\
\hline P1-2 & $47^{\circ} \mathrm{N}, 147^{\circ} \mathrm{W}-126^{\circ} \mathrm{W}$ & $0.29 *$ & 0.130 \\
\hline $\mathrm{P} 1-3$ & $47^{\circ} \mathrm{N}, 147^{\circ} \mathrm{W}-126^{\circ} \mathrm{W}$ & $0.32 *$ & 0.091 \\
\hline $\mathrm{P} 4-2$ & $9.3^{\circ} \mathrm{N}, 160^{\circ} \mathrm{E}-160^{\circ} \mathrm{W}$ & 0.62 & 0.074 \\
\hline P4-3 & $9.3^{\circ} \mathrm{N}, 165^{\circ} \mathrm{W}-110^{\circ} \mathrm{W}$ & 0.54 & 0.062 \\
\hline $\mathrm{P} 4-4$ & $9.3^{\circ} \mathrm{N}, 160^{\circ} \mathrm{E}-160^{\circ} \mathrm{W}$ & 0.51 & 0.053 \\
\hline P6W & $30^{\circ} \mathrm{S}, 154^{\circ} \mathrm{E}-178^{\circ} \mathrm{E}$ & 0.66 & 0.052 \\
\hline P6C & $32.3^{\circ} \mathrm{S}, 165^{\circ} \mathrm{W}-120^{\circ} \mathrm{W}$ & 0.55 & 0.060 \\
\hline P6E & $32.3^{\circ} \mathrm{S}, 110^{\circ} \mathrm{W}-88^{\circ} \mathrm{W}$ & 0.56 & 0.073 \\
\hline P16S & $33^{\circ} \mathrm{S}-17^{\circ} \mathrm{S}, 150.3^{\circ} \mathrm{W}$ & 0.50 & 0.067 \\
\hline $\mathrm{P} 16 \mathrm{C}$ & $17.3^{\circ} \mathrm{S}-9.3^{\circ} \mathrm{N}, 150.6^{\circ} \mathrm{W}$ & 0.72 & 0.116 \\
\hline P17S & $19^{\circ} \mathrm{C}-6^{\circ} \mathrm{S}, 134^{\circ} \mathrm{W}$ & 0.51 & 0.124 \\
\hline $\mathrm{P} 17 \mathrm{C}-2$ & $6^{\circ} \mathrm{S}-0.4^{\circ} \mathrm{N}, 134.6^{\circ} \mathrm{W}$ & 0.44 & 0.067 \\
\hline $\mathrm{P} 17 \mathrm{C}-3$ & $0.4^{\circ} \mathrm{N}-34.4^{\circ} \mathrm{N}, 134.6^{\circ} \mathrm{W}$ & 0.82 & 0.105 \\
\hline PR3 & $34^{\circ} \mathrm{N}-42.2^{\circ} \mathrm{N}, 144^{\circ} \mathrm{E}$ & 1.36 & 0.120 \\
\hline PR13J & $25^{\circ} \mathrm{N}-48^{\circ} \mathrm{N}, 165^{\circ} \mathrm{E}$ & 0.78 & 0.160 \\
\hline PR13N & $43.2^{\circ} \mathrm{S}, 148^{\circ} \mathrm{E}-166^{\circ} \mathrm{E}$ & $1.41^{*}$ & 0.065 \\
\hline PR16 & $1^{\circ} \mathrm{N}-6^{\circ} \mathrm{N}, 110^{\circ} \mathrm{W}$ & 1.01 & 0.150 \\
\hline PR20 & $21.5 \mathrm{~N}$ & 0.87 & 0.071 \\
\hline
\end{tabular}

* Temperature (but not salinity) from these cruises has been assimilated in the control analysis.

the whole tropical belt $15^{\circ} \mathrm{S}-15^{\circ} \mathrm{N}$ the rms difference is around $4.0 \mathrm{~cm}$.

The rms difference increases in regions of high eddy generation such as the regions of western boundary current extensions and in the Antarctic Circumpolar Current. A few "bull's-eyes" appear in Fig. 3a. Close examination shows that these result from mislocated XBTs that are then inconsistent with altimeter sea level. One example of a mislocated XBT is at $18^{\circ} \mathrm{N}, 185^{\circ} \mathrm{W}$ in Fig. 3a. The rms difference for the full $62^{\circ} \mathrm{S}-62^{\circ} \mathrm{N}$ domain is $5.2 \mathrm{~cm}$.

When altimetric sea level is used as a constraint on the analysis temperature and salinity fields (but not pressure since pressure is not a prognostic model variable), the rms difference is reduced by $1-2 \mathrm{~cm}$ (Fig. 3b). In the tropical Atlantic and Pacific the differences lie in the range $2-3 \mathrm{~cm}$. The average for the full tropical belt $15^{\circ} \mathrm{S}-15^{\circ} \mathrm{N}$ becomes $3.1 \mathrm{~cm}$. In the mesoscale eddy production regions of the midlatitudes the rms difference again increases due to limitations in model physics and poorer error statistics.

\section{b. WOCE hydrographic transects}

The World Ocean Circulation Experiment is an international program designed to define the large-scale 
(a)

TEMPERATURE DIFFERENCE (WOCE-ANAL.)
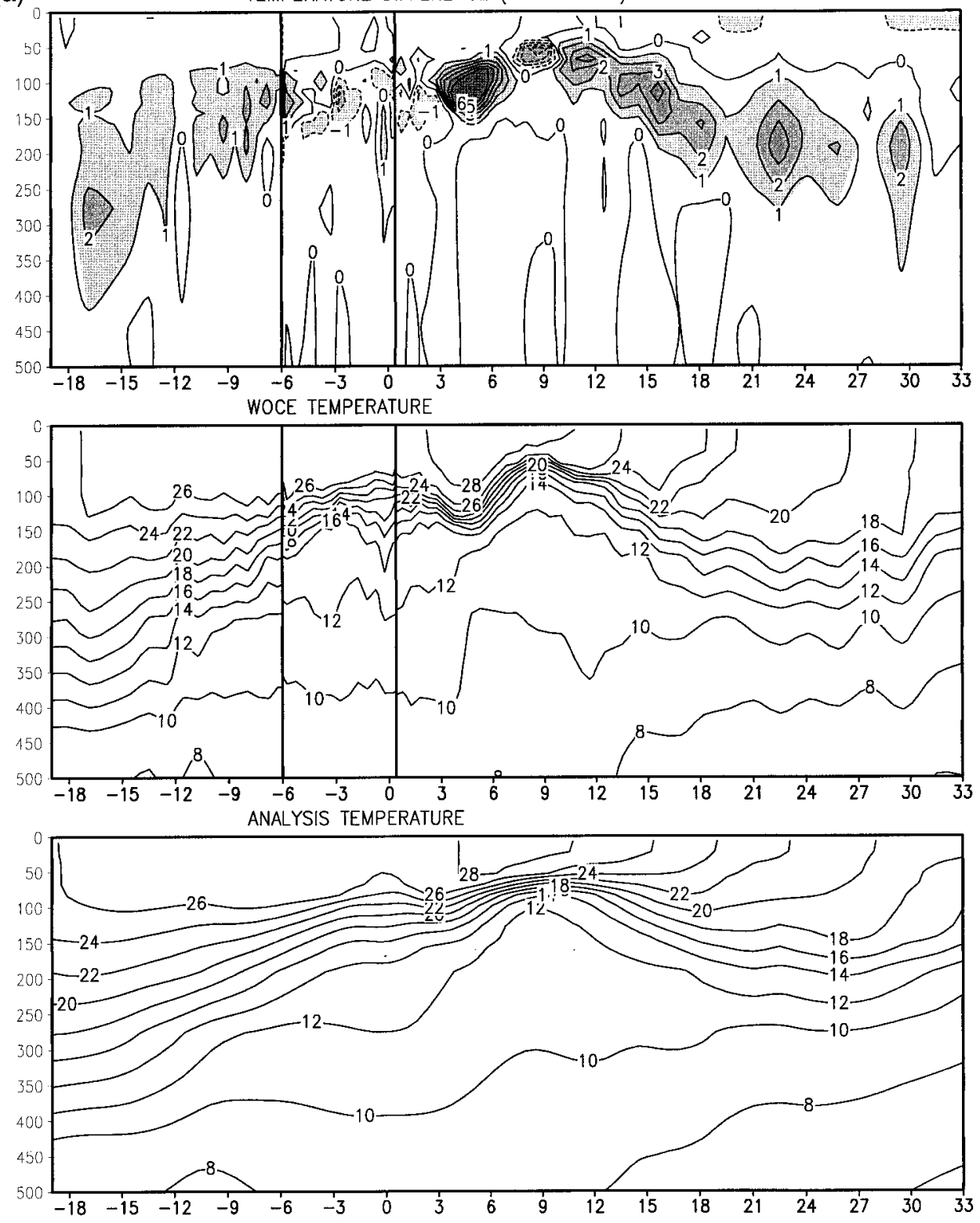

FIG. 4. Temperature and salinity with depth along WOCE meridional transect P17 near longitude $134^{\circ} \mathrm{W}$ in the eastern Pacific Ocean during June-July 1991. The observed transect was made of three sections. Upper panel shows the difference between observed and control analysis, middle panel shows observations, lower panel shows analysis. (a) Temperature and (b) salinity.

structure of the ocean. The field program, including a broad array of observations, has been concentrated during the period since 1989. A primary dataset consists of a series of high quality one-time hydrographic surveys transecting the major oceans with some repeat sections. With the exceptions noted below, this dataset was not included in the data archive of Levitus et al. (1994) and consequently provides us with wonderful independent data for comparison.

Not all of the WOCE hydrography is publicly available. From the more limited set of data available from the Scripps Institution of Oceanography mirror site of the WOCE hydrographic program Special Analysis Center in Hamburg, we have extracted 16 transects listed in Table 3. The temperature and salinity data along each transect has been linearly interpolated on constant depth surfaces to the model grid coordinates and then compared to the monthly averaged temperature and salinity fields from the control analysis. Along each section the rms difference between observed and control analysis temperature and salinity has been computed at the model levels and averaged in depth and distance 
(b)
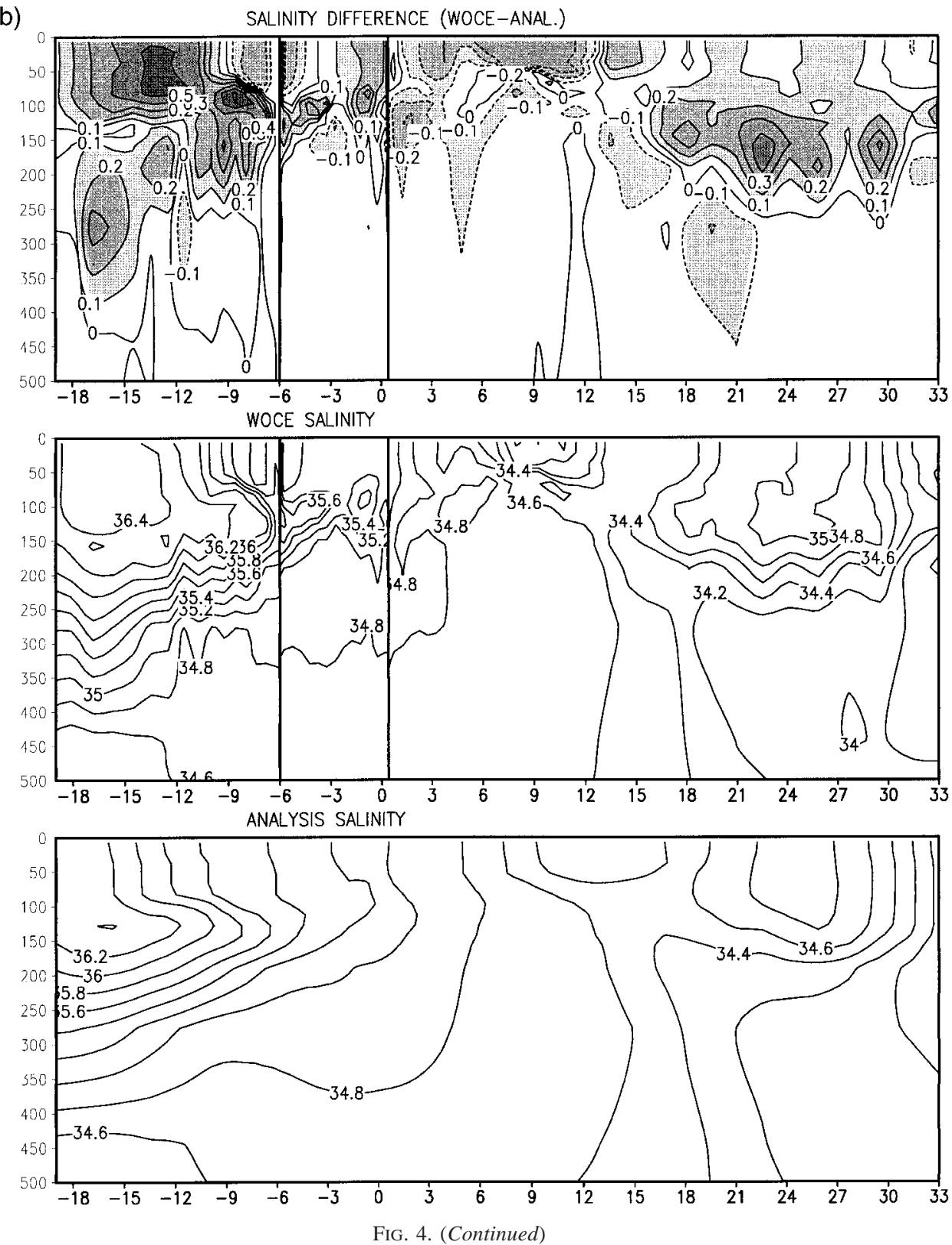

TABLE 4. Rms near-surface anomalous observed velocity components and rms differences between anomalous observed and analysis velocity components. Zonal and meridional anomalous velocity components are computed with respect to the 1988-93 monthly climatology and averaged over the Pacific basin between $30^{\circ} \mathrm{S}$ and $40^{\circ} \mathrm{N}$ Units: centimeters per second.

\begin{tabular}{lcccc}
\hline \hline Year & $\mathrm{Rms}\left(u^{\prime}\right)$ & $\mathrm{Rms}\left(v^{\prime}\right)$ & $\mathrm{Rms}\left(\Delta u^{\prime}\right)$ & $\mathrm{Rms}\left(\Delta v^{\prime}\right)$ \\
\hline 1988 & 25.4 & 15.2 & 16.7 & 11.3 \\
1989 & 20.4 & 13.3 & 17.0 & 10.1 \\
1990 & 19.0 & 12.7 & 13.5 & 9.3 \\
1991 & 21.3 & 12.1 & 14.1 & 9.5 \\
1992 & 20.6 & 12.9 & 13.5 & 8.9 \\
1993 & 21.5 & 12.5 & 12.1 & 8.9 \\
$1988-93$ & 20.6 & 12.4 & 13.3 & 8.9 \\
\hline
\end{tabular}

along the cross section. In some cases the transects have been decomposed into smaller sections when they span more than a single month.

The large error in temperature for A11 can be understood because of its location in the poorly sampled Southern Hemisphere and the high degree of eddy variability. The errors for PR3 in the subtropical North Pacific and PR16 in the tropical Pacific are more surprising. The transects with large salinity errors generally have two kinds of errors. Either the salinity errors are large in the mixed layer (PR3, AR15, AR4E), indicating problems with surface fluxes, or the errors are confined below the mixed layer. Two of the transects with substantial salinity errors below the mixed layer (P1, 
V' CONTROL 1991

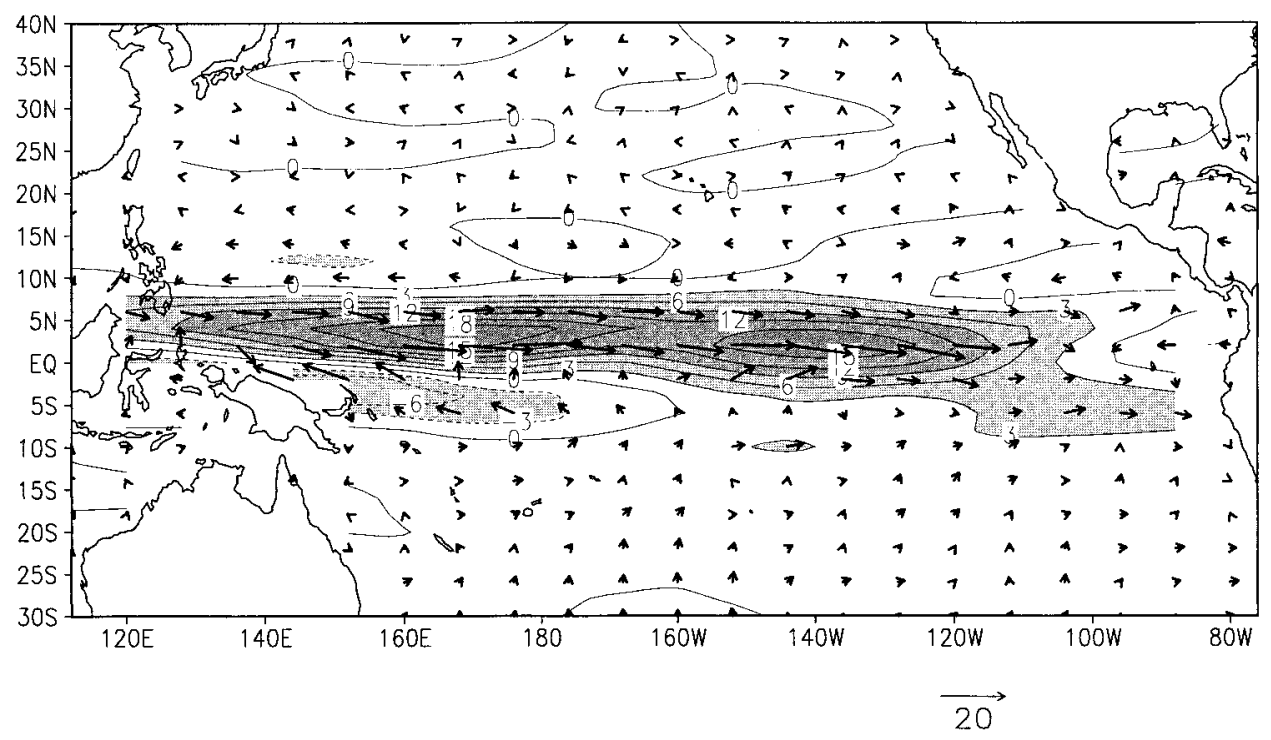

V' DRIFTERS 1991

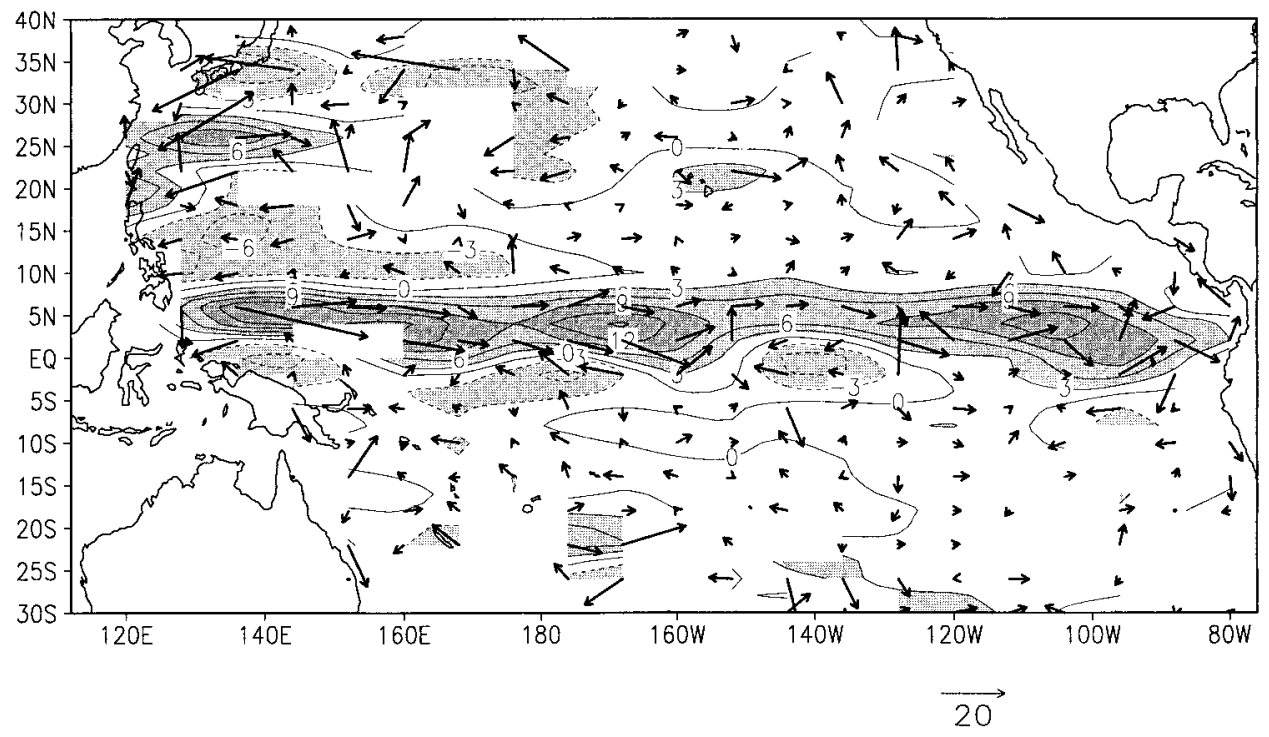

FIG. 5. Comparison of anomalous observed and control analysis near-surface annual-averaged anomalous currents in the tropical Pacific for the year 1991. Upper panel shows observations the control analysis, while lower panel shows currents from currents based on drifter. Anomalous currents have been computed relative to the 1988-93 monthly climatology. Observed and analysis tropical currents show a distinctive eastward anomaly during this year.

PR13J) do not have large corresponding errors in temperature, suggesting that the salinity errors are the result of errors in horizontal advection.

One particularly interesting transect, labeled $\mathrm{P} 17$, cuts through the eastern Pacific from $19^{\circ} \mathrm{S}$ to $34^{\circ} \mathrm{N}$. This transect was broken into several segments that are separated by vertical lines in Figs. 4a,b. At subtropical latitudes comparison of observed and analysis temper- ature fields shows that the most significant error is at thermocline depths. Analysis temperature is too low by $1^{\circ}-2^{\circ} \mathrm{C}$ suggesting that the thermocline is too shallow by $10-20 \mathrm{~m}$. The largest error is between $3^{\circ} \mathrm{N}$ and $8^{\circ} \mathrm{N}$. This band of latitudes corresponds to the North Equatorial Countercurrent trough that separates the northern extension of the South Equatorial Current from the North Equatorial Countercurrent. Weakness in the 
trough implies that the transports in these two currents are weak.

Comparison of observed and analysis salinity fields also shows that significant error is present at thermocline depths as well as in the mixed layer (Fig. 4b). South of the equator the observed transect shows evidence of subduction and equatorward transport of high salinity subtropical water. The observed salinity maximum is narrowly confined in depth within a few degrees of the equator. In contrast, the analysis salinity shows a broader, weaker subsurface salinity maximum. This difference indicates that the analysis is subducting subtropical water, but not as rapidly as is observed. One factor may be that the mixed layer salinity reaches a maximum of $36.2 \mathrm{psu}, 0.2 \mathrm{psu}$ lower than observed. In contrast, the analyzed mixed layer salinity between $6^{\circ}$ and $12^{\circ} \mathrm{N}$ is more than 0.2 psu higher than observed. In summary, the major sources of error include those associated with errors in the mixed layer and subduction processes, large-scale bias, and unresolved mesoscale variability.

\section{c. Surface drifters}

The most extensive spatial coverage of velocity measurements is provided by the WOCE/TOGA surface drifter velocity program (Niiler et al. 1999, manuscript submitted to J. Phys. Oceanogr.). Although some measurements were collected in the early 1980s, extensive coverage is only available since 1988 . We have obtained the data presented here from the Atlantic Oceanographic Marine Laboratory/NOAA, where the drifter data has been converted to Eulerian velocities and averaged into $8^{\circ} \times 2^{\circ} \times 1$ month bins. We compute velocity anomalies by removing the 1988-93 monthly climatology from the observations and analyses. Table 4 shows the spatial average of the rms velocity anomaly components, as well as the rms differences between observed and analysis anomalous velocity components for each year. We approach this comparison with trepidation since nearsurface velocity is a difficult field to simulate. The 6yr averages show that the rms anomalous zonal velocity difference $\left(13.3 \mathrm{~cm} \mathrm{~s}^{-1}\right)$ is $30 \%$ less than the rms zonal velocity itself $\left(20.6 \mathrm{~cm} \mathrm{~s}^{-1}\right)$. Some similarity in observed and analysis variability is present in almost every year in both zonal and meridional components.

The spatial pattern of anomalous velocity for 1991, the year of the beginning of a strong El Niño, is shown in Fig. 5. The surface velocity during this year is characterized by a strong $10 \mathrm{~cm} \mathrm{~s}^{-1}$ eastward surge along and just north of the equator in response to the relaxation of the trade winds [see Frankignoul et al. (1996) for discussion of the surge]. South of the equator and north of $10^{\circ} \mathrm{N}$ the velocity is weakly westward. In the extratropics the observed velocity components are confused. The control analysis velocity also shows an eastward surge of water of somewhat higher amplitude than observed, extending not quite as far toward the coast of South America. North and south of this surge westward
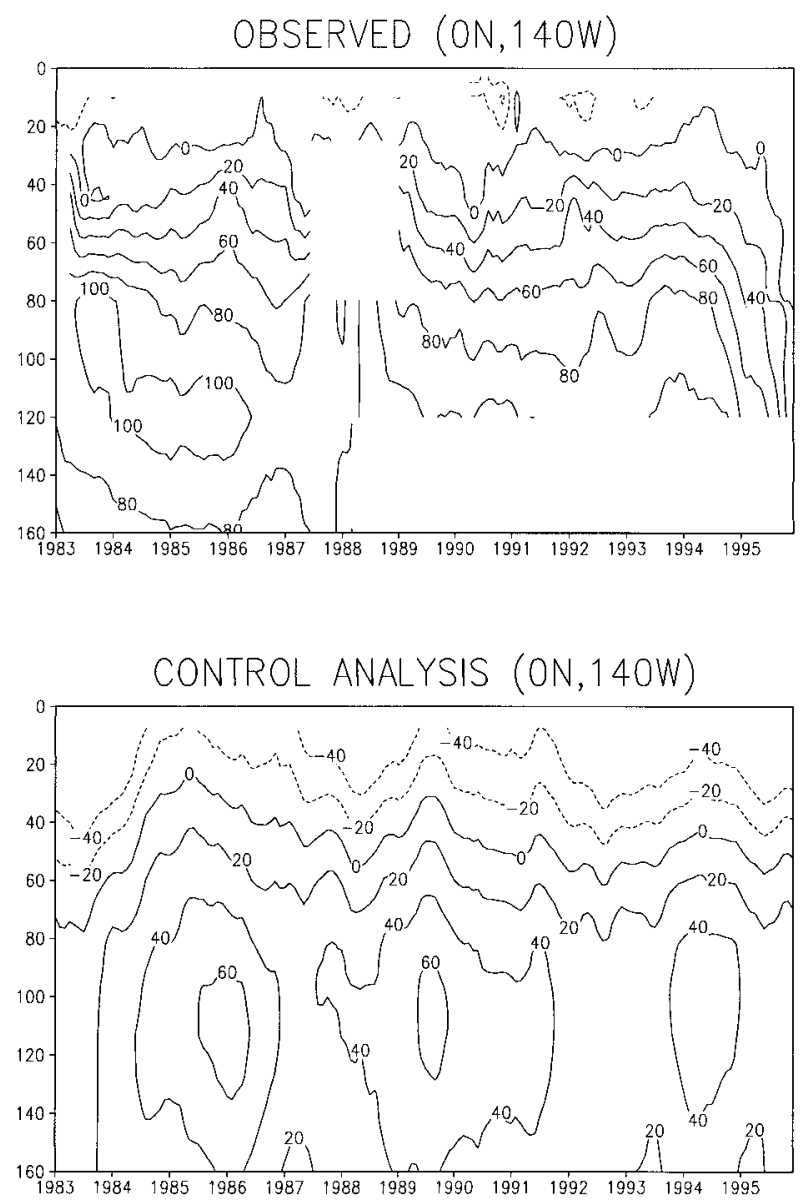

FIG. 6. Comparison of observed and control analysis zonal current time series on the equator with depth at $140^{\circ} \mathrm{W}$ in the eastern Pacific. Note the presence of strong interannual variability associated with El Niño.

return currents are apparent, as observed. The analysis velocity in the extratropics is of lower amplitude than observed. We think that the reduced amplitude of analyzed velocity at the oceanic mesoscale is the result of dissipation of mesoscale eddies by the forecast model.

\section{d. Equatorial Pacific moored current}

The anomalous eastward surface velocity at the equator during 1991 has corresponding subsurface changes. In Fig. 6 we compare observed current from the Tropical OceanAtmosphere mooring maintained by the Pacific Marine Environmental Laboratory at $140^{\circ} \mathrm{W}$. At this longitude, close to the longitude of the section P17 shown in Fig. 4, the westward South Equatorial Current is confined to the upper $40 \mathrm{~m}$ where its annual average speed rarely exceeds $-20 \mathrm{~cm} \mathrm{~s}^{-1}$. During 1991 the South Equatorial Current shoals to $20 \mathrm{~m}$ and actually disappears early in the year. The analysis velocity at the same longitude as the mooring shows a significant westward bias (Fig. 4). Thus, the South Equatorial Current is too strong and the Equatorial Un- 

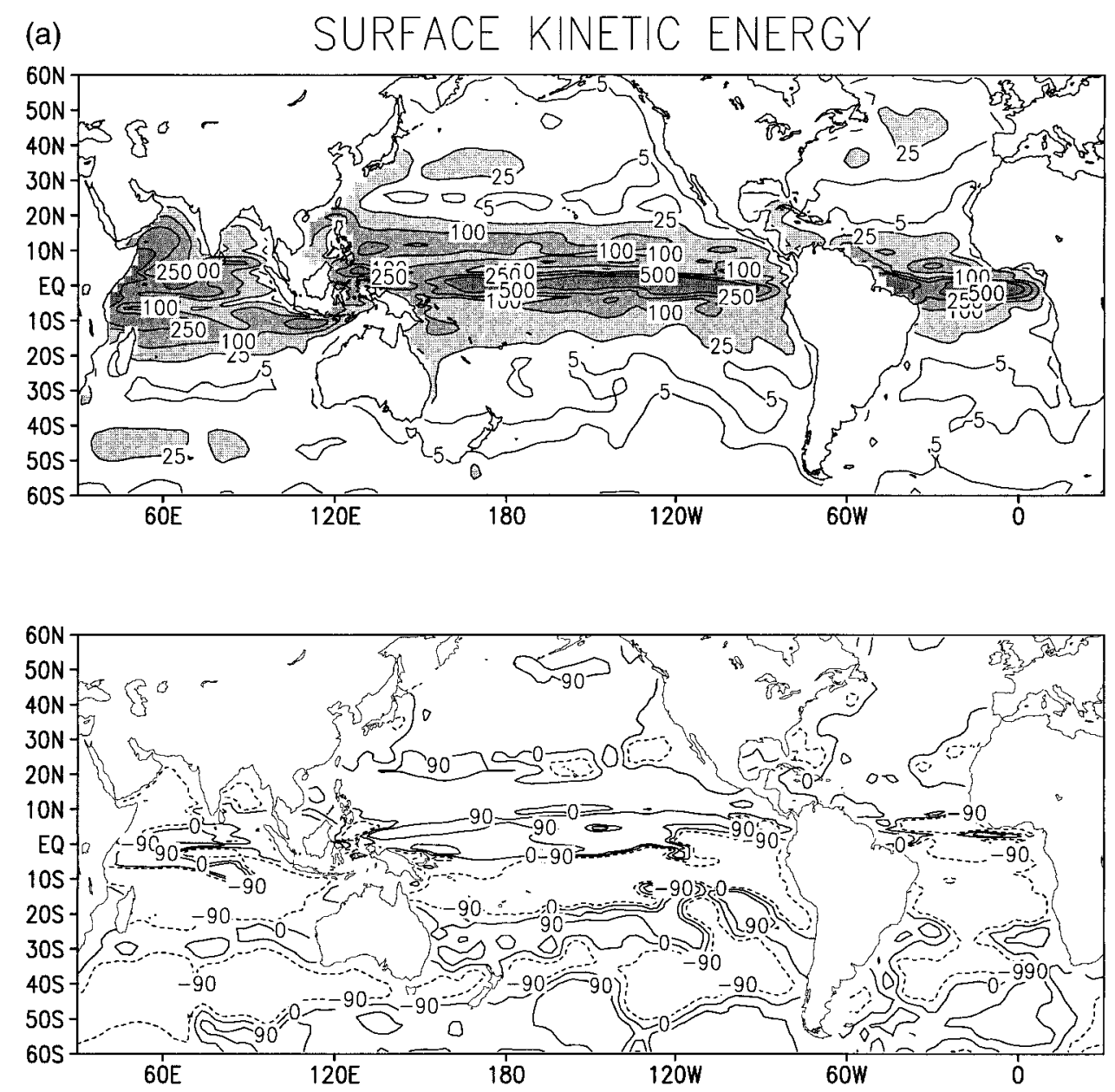

FIG. 7. Annual cycle of (a) kinetic energy and (b) sea level from the control analysis. The annual cycle is defined as the annual harmonic of the Fourier series. Sea level has strong annual amplitude in the high variability regions of the western boundary current. The maximum amplitude in these regions approaches $15 \mathrm{~cm}$. Units are $\mathrm{m}^{2} \mathrm{~s}^{-2}$ and $\mathrm{cm}$.

dercurrent velocity is too weak at this location. The control analysis surface South Equatorial Current is relatively weak during 1991, while the Equatorial Undercurrent does not weaken until 1992. From these results and additional experiments we conclude that better meridional resolution and stronger trade winds are required to improve the analysis of tropical currents.

\section{Global statistics}

The strongest signal in the mass and momentum fields is the annual shift of heat and mass in response to shifting winds and surface heat flux. We introduce our statistical analysis by discussing the annual cycle of two key quantities, surface kinetic energy $\left(u^{2}+v^{2}\right) / 2$ and sea level based on the 46-yr control analysis (Figs. 7a,b). The annual cycle of a third variable, heat content, will be discussed separately. The basin-scale structure of the annual cycle of sea level is dominated by a pattern of rising level in the summer hemisphere as a result of the antisymmetry about the equator of winds and solar heating. Smaller-scale variations are also evident. Western boundary current regions of the North Atlantic and North Pacific have seasonal amplitudes approaching 15 $\mathrm{cm}$ (these results closely resemble those computed from short 1-yr-long altimeter records by Cheney et al. 1994). The Tropics also have distinct smaller-scale features. The tropical Atlantic and Pacific show 4-6 cm variations in zonal bands resulting from seasonal changes in the North Equatorial Countercurrent. The corresponding amplitude of heat content in these regions (not shown) is $200^{\circ} \mathrm{C} \mathrm{m}$.

In contrast to sea level the annual cycle of kinetic energy (Fig. 7b) is largest in the Tropics, reflecting the seasonal changes in the tropical current system. The annual amplitude of these currents exceeds $20 \mathrm{~cm} \mathrm{~s}^{-1}$. In the tropical Pacific the intensity of the current is reduced somewhat near $140^{\circ} \mathrm{W}$. The annual kinetic en- 

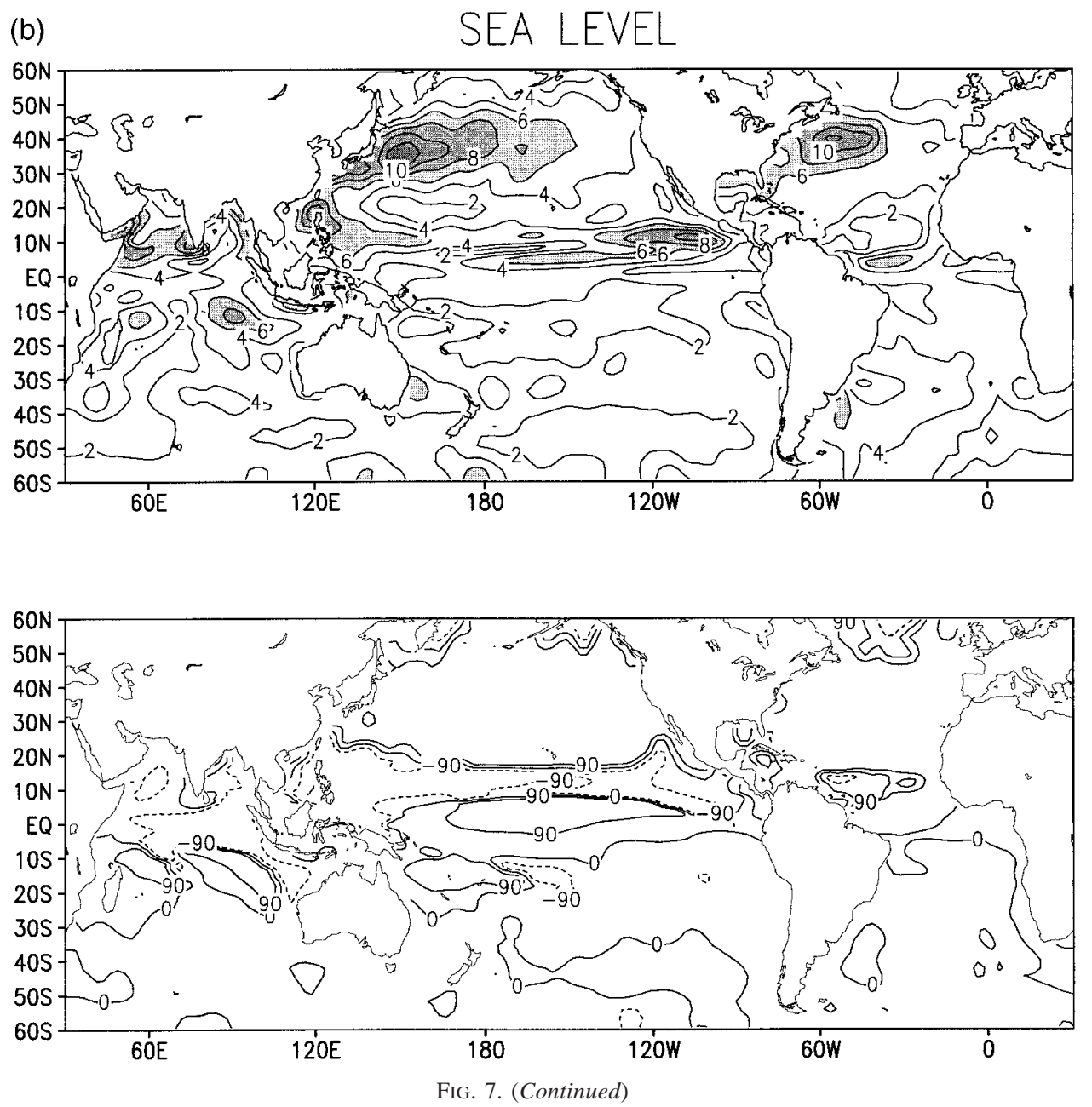

ergy in the Indian Ocean is elevated throughout, with highest values along the western boundary in the region of the seasonal Somali Current.

Seasonal variations in local heat storage, the time rate of change of heat content, reflect the difference between net surface heating and horizontal divergence of heat transport. Because the ocean basins are bounded to the east and west at most latitudes, the zonal average of heat storage, shown in Figs. 8a-c for the three basins, is the difference between net surface heating and the meridional divergence of heat transport. Here storage is computed by taking the center difference from successive monthly averages. These results can be directly compared with the results of Hsiung et al. (1989). Heat storage to a shallower $275-\mathrm{m}$ depth, but using the expanded WOA-94 dataset, is presented in Levitus and Antonov (1997). Heat storage in the Pacific follows the cycle of solar radiation with a maximum in the Northern Hemisphere in June-August. The seasonal maximum is somewhat lower than in either of the two previous studies. Maximum heat loss from the Southern Hemisphere occurs perhaps a few weeks earlier and is of significantly lower amplitude than Levitus and Antonov. The pattern of heat storage near the equator resembles that of Levitus and Antonov with a complex set of zonal bands of heat gain and loss. The period July-October is one in which the region from $10^{\circ} \mathrm{S}-0^{\circ}$ is storing heat rapidly as a result of the appearance of the cold tongue in the eastern Pacific, while the region from $0^{\circ}-10^{\circ} \mathrm{N}$ is losing heat rapidly.

Heat storage in the Atlantic (Fig. 8b) generally resembles heat storage in the Pacific. In the North Atlantic maximum heat storage occurs somewhat earlier (MayJuly). Heat is being exported mainly during early boreal summer. In the tropical Atlantic rapid heat storage is limited to the months June-September. South of the equator storage occurs during September-February. Heat storage in the tropical Indian Ocean (Fig. 8c) is quite complicated. Between $20^{\circ} \mathrm{S}$ and $5^{\circ} \mathrm{S}$ the southern Indian Ocean is gaining heat during June-October, a period in which the sun is actually in the Northern Hemisphere. This region is losing heat during NovemberMarch, a period in which the sun has crossed over into the Southern Hemisphere! These counterintuitive results are generally consistent with those of Hsiung et al. (1989) and Levitus and Antonov (1997). 

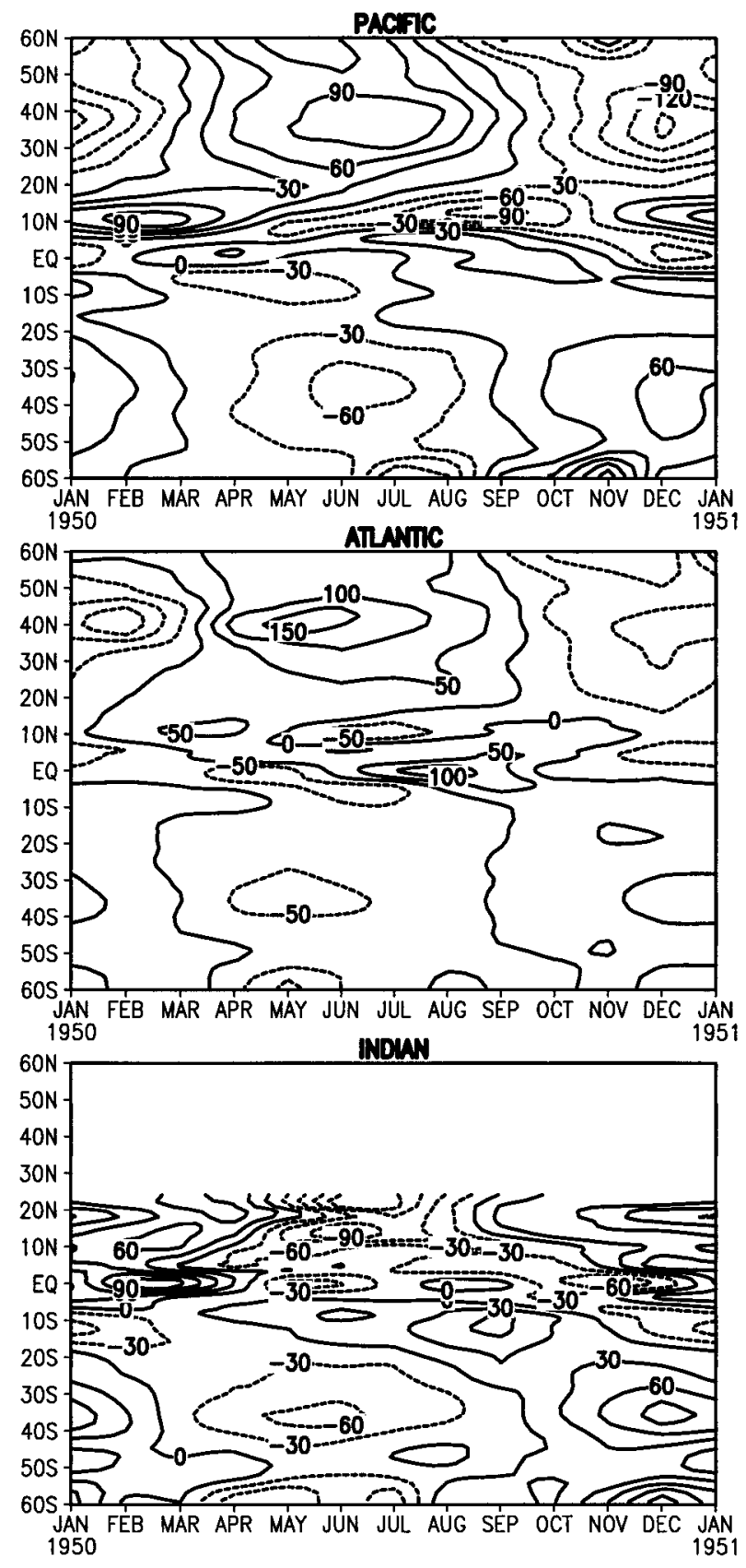

FIG. 8. Zonal average of monthly climatological $0 / 500 \mathrm{~m}$ heat storage for the three ocean basins. Positive values indicate that the ocean is gaining heat. Units are ${ }^{\circ} \mathrm{C} \mathrm{m} \mathrm{mo}{ }^{-1}$.

At periods longer than the annual cycle the distribution of variance changes. In Fig. 9 we present a crude decomposition of the spectral characteristics of the heat content field by separating the variability into an interannual band (1-5 yr) and a decadal band (5-25 yr). At interannual periods the variability along the equator in the Pacific is enhanced and shifted eastward, while offequatorial variability occurs in the western side of the basin. The western tropical Indian Ocean has significant variability, as do the eddy production regions of the western boundary currents and Antarctic Circumpolar Current. At decadal periods the Tropics become less prominent relative to the subtropical and midlatitude gyres. The shift of variability from the Tropics toward midlatitude as the frequency decreases reflects the fundamental dynamical properties of the ocean.

Much of the heat content variability at interannual and decadal periods in Fig. 9 is spatially incoherent. In order to explore the sources of just that part of the heat content signal that has basin scales we define three focal areas, one in the central North Pacific (averaged, $30^{\circ}-$ $\left.45^{\circ} \mathrm{N}, 180^{\circ}-210^{\circ} \mathrm{W}\right)$, a second in the eastern tropical Pacific (averaged $5^{\circ} \mathrm{S}-5^{\circ} \mathrm{N}, 150^{\circ}-90^{\circ} \mathrm{W}$ ), and a third in the central North Atlantic (averaged $25^{\circ}-40^{\circ} \mathrm{N}, 70^{\circ}-$ $30^{\circ} \mathrm{W}$ ). Note that the focal area in the North Atlantic is smaller than the others, reflecting the smaller spatial scales of variability there. The time series of area-averaged heat content anomaly are presented in Fig. 10 (a linear trend has been removed, consistent with the previous analysis). In order to define the spatial structure of these modes we correlate the three heat content anomaly time series with heat content anomaly throughout the global ocean. The three resulting correlation maps are shown in Fig. 11.

The time series and spatial pattern of correlation with North Pacific heat content is shown in the upper panels of Figs. 10 and 11. The variability is substantially decadal. The most prominent feature of the time series is a cooling during the 1980 s following a relatively warm 1970s. Heat content variability in the North Pacific has been related to fluctuations in the Pacific-North America pattern of wind variation (Trenberth and Hurrell 1994; Graham 1994). Changes in the wind patterns in 1976-77 led to a cooling in the central basin that was referred to as a climate shift by Miller et al. (1994). This climate shift is evident in Fig. 10 but is followed 11 years later by a return to warm conditions, also noted by Levitus and Antonov (1995).

By correlating the North Pacific time series with heat content anomaly time series for the rest of the oceans we can identify the spatial pattern of oceanic thermal variability. The region that is most highly correlated with the midlatitude North Pacific, interestingly, is the western tropical and southern Pacific. Much of the correlation results from a drop in heat content in the 1970s that approximately coincides with the drop in the central North Pacific. Between these two regions of positive correlation is a region of negative correlation. This pattern of alternating positive and negative correlation is reminiscent of ideas of a slow advection of thermal anomalies throughout the North Pacific (e.g., Latif and Barnett 1994; Deser et al. 1996).

Next we turn our attention to the tropical Pacific. The variability here is strongly interannual, reflecting the importance of El Niño. Individual peaks in the time series can be identified with individual El Niños. Examination of the time series shows that the amplitude 

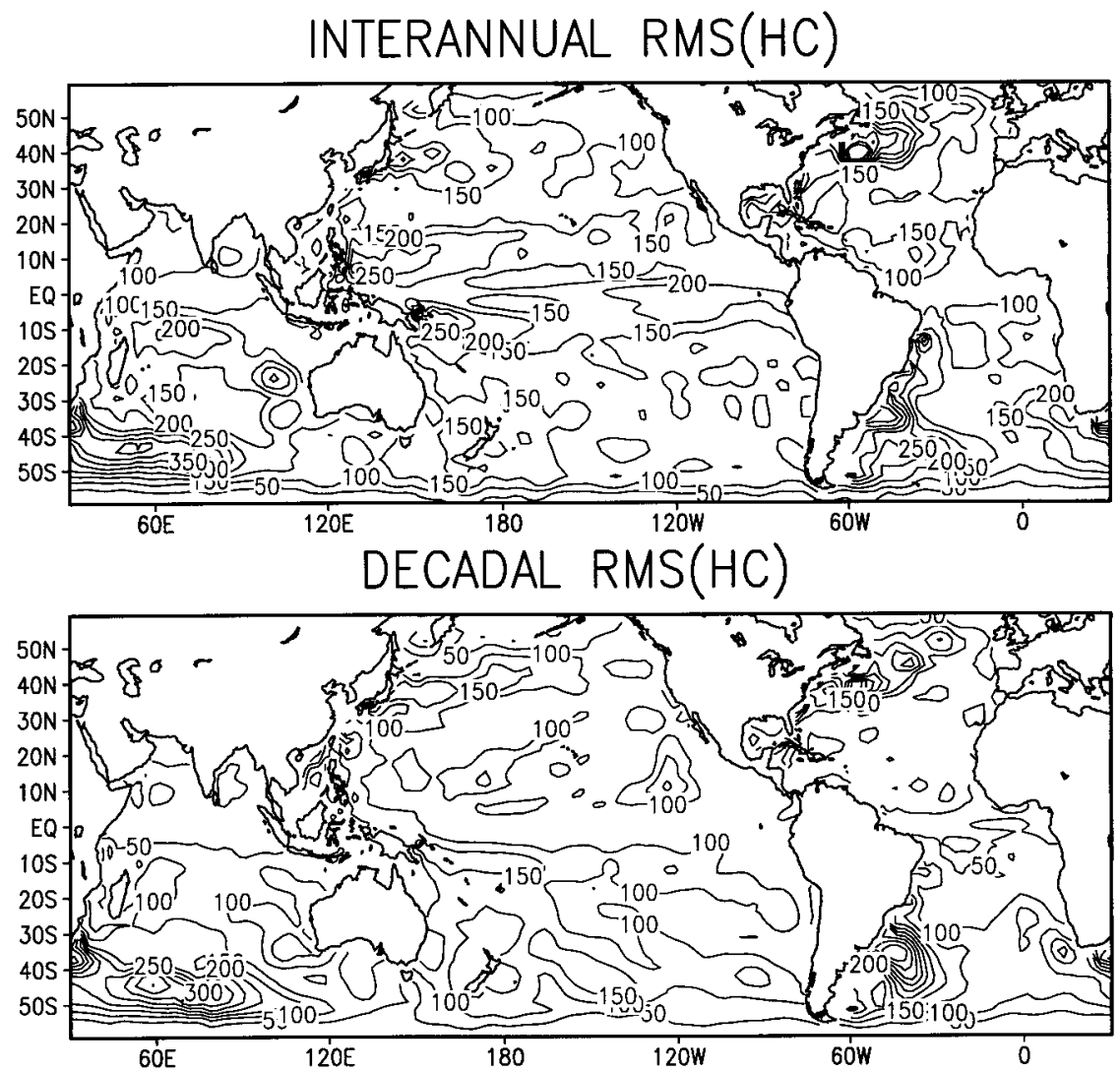

FIG. 9. Root-mean-square $0 / 500 \mathrm{~m}$ heat content variability in the (a) interannual band (1-5 yr) and (b) decadal band (5-25 yr). Units are ${ }^{\circ} \mathrm{C} \mathrm{m}$.

and frequency of heat content variability has been fairly regular during the past five decades. Decadal variability is also evident in the time series. The late 1970s were a period of gradual warming coinciding with a warming of SST (Wang 1995).

Examination of the spatial pattern of correlation with tropical Pacific heat content shows the spatial structure of the oceanic expression of El Niño. For example, we find that on either side of the zonal band of high correlation near the equator are bands of negative correlation. The band of negative correlation in the Northern Hemisphere is most coherent, extending west-southwestward from the west coast of North America. The existence of off-equatorial bands of negative correlation is a key feature of the delayed-oscillator theories of the periodicity of El Niño. The zone of negative correlation extends into the eastern Indian Ocean, suggesting a connection between the western Pacific and eastern Indian Ocean. Examination of the lagged correlation shows that the band of positive correlation near the equator shifts eastward and poleward with time, while the off-equatorial bands of negative correlation shift westward.

The impact of El Niño on the North and tropical Atlantic has been examine in a number of studies (e.g., Carton and Huang 1994; Enfield and Meyer 1997). In the tropical Atlantic Carton and Huang have proposed that the changes in western tropical Atlantic winds associated with warm SST in the eastern tropical Pacific leads to a buildup of heat in the western tropical Atlantic. This anomalous heat, which occurs in the form of anomalous deepening of the thermocline, eventually leads to a deepening of the equatorial thermocline and contributes to warming in the eastern Atlantic. Some confirmation for these ideas is apparent in the weakly positive correlation (0.2) between eastern tropical $\mathrm{Pa}-$ cific heat content and western tropical Atlantic heat content.

The final time series in the lower panel of Fig. 10 represents the central North Atlantic Ocean. Heat content variability in the North Atlantic is also associated with variability in the sector winds, in this case the North Atlantic Oscillation pattern Atlantic winds (Hurrell and van Loon 1997). The time series of heat content shows rich decadal variability. The 1950s are relatively warm, followed by a series of cool events in the early 1960s, the late 1960s and early 1970s, and again in the late 1970s and early 1980s. The second of these cool events has been documented by S. Levitus (Levitus 1990).

\section{Conclusions}

In a companion to this study Carton et al. (2000) present a five-decade-long historical analysis of global 

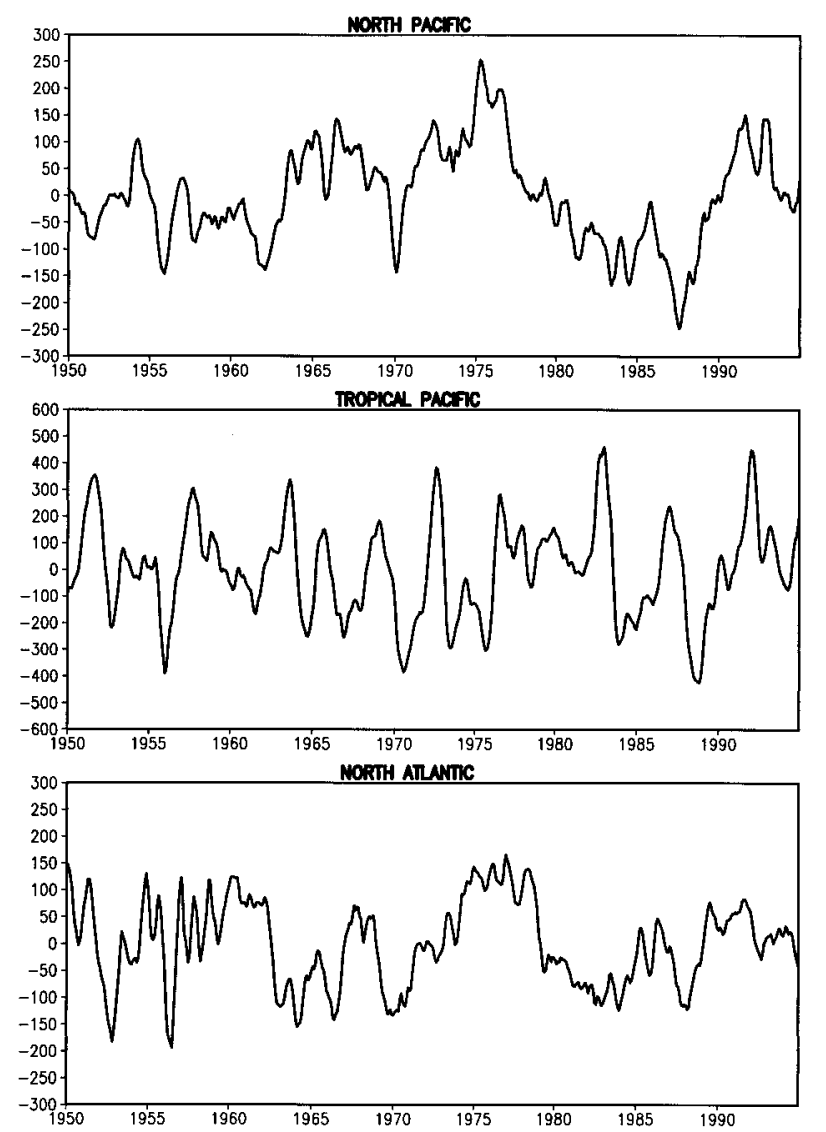

FIG. 10. Time series of heat content anomaly from the seasonal cycle for three regions, (a) North Pacific (averaged, $30^{\circ}-45^{\circ} \mathrm{N}, 180^{\circ}$ $210^{\circ} \mathrm{W}$ ), (b) Nino3 region of the eastern tropical Pacific (averaged $5^{\circ} \mathrm{S}-5^{\circ} \mathrm{N}, 150^{\circ}-90^{\circ} \mathrm{W}$ ), and (c) North Atlantic (averaged $25^{\circ}-40^{\circ} \mathrm{N}$, $70^{\circ}-30^{\circ} \mathrm{W}$ ). The regions are indicated in the corresponding panels of Fig. 11. Units are ${ }^{\circ} \mathrm{C} \mathrm{m}$.

upper-ocean temperature, salinity, sea level, and currents. The purpose of the analysis is to provide a uniformly gridded historical dataset for use in studies of the ocean's role in climate. Two ways to quantify the accuracy of the analysis are by direct comparison to independent observations and by examining identifiable climate features such as the annual cycle, El Niño, and the Pacific-North American anomaly. Here we take both approaches.

We begin with a comparison to time series with limited spatial coverage and to global observation sets with limited temporal coverage. The island tide-gauge time series suggests that the analysis explains $25 \%$ of the observed sea level variance at longer than annual frequencies and more than 30\% in the frequency band between 5 and 25 years. The explained variance increases in the tropical Pacific. Comparison to satellite altimeter sea level shows a root-mean-square difference of $4.0 \mathrm{~cm}$ in the Tropics $15^{\circ} \mathrm{S}-15^{\circ} \mathrm{N}$ and $5.2 \mathrm{~cm}$ globally when this dataset is not assimilated. When altimetry is assimilated, the rms difference in the tropical sea level decreases to $3.1 \mathrm{~cm}$. The comparison to a series of global hydrographic sections shows average temperature and salinity errors in the upper $500 \mathrm{~m}$ of $0.70^{\circ} \mathrm{C}$ and 0.092 psu. The temperature errors are mainly concentrated at thermocline depths. Salinity errors are distributed through the mixed layer and pycnocline. A comparison to moored and surface drifter velocity shows the analysis reproduces the qualitative behavior of surface velocity in the Tropics.

We begin the discussion of climate features by consideration of the annual cycle. At the annual period both hemispheres show a strong response to seasonal forcing of surface winds, heat, and freshwater. In the subtropics and midlatitudes sea level varies in phase with seasonal changes in solar radiation, except in the southern Indian Ocean. Closer to the equator the phase of sea level undergoes rapid reversals as the ocean responds to strong annual variations in winds. The implied rates of heat storage are consistent with previous studies.

The strongest basin-scale signal at interannual periods is associated with El Niño. To explore this pattern of variability we examine the correlation of global heat content with the heat content time series from a region of the eastern equatorial Pacific (the Nino3 region) that is itself considered an index of El Niño. Our examination of the zero-lag correlation of global heat content shows the eastern and western tropical Pacific to be out of phase (correlation -0.4 to -0.6 ). The eastern Indian Ocean is in phase with the western Pacific and thus is out of phase with the eastern Pacific. The North Pacific has a weak positive correlation with the eastern equatorial Pacific. Correlations between eastern Pacific heat content and Atlantic heat content are modest.

At longer decadal periods the Pacific-North America wind pattern leads to broad patterns of correlation in heat content variability. Increases in heat content in the central North Pacific are associated with decreases in heat content in the subtropical Pacific and increases in the western tropical Pacific. Atlantic heat content is positively correlated with the central North Pacific. The Atlantic-Pacific relationship is confirmed by correlating the heat content anomaly in the central North Atlantic with global heat content.

In several respects the analysis is clearly inconsistent with the observations. Major problems include:

1) The inability of the forecast model to produce thermocline water masses in sufficient volume. Two examples of this problem are identified, the subtropical mode water of the North Atlantic and the high salinity subtropical water that enters the equatorial thermocline from the south in the Pacific and Atlantic. Interannual changes in these water masses change the covariances of temperature and salinity errors, and thus violates an assumption of our analysis. The major causes of insufficient thermocline water-mass production are still not clear. Adjoint or streamline assimilation techniques together with is- 

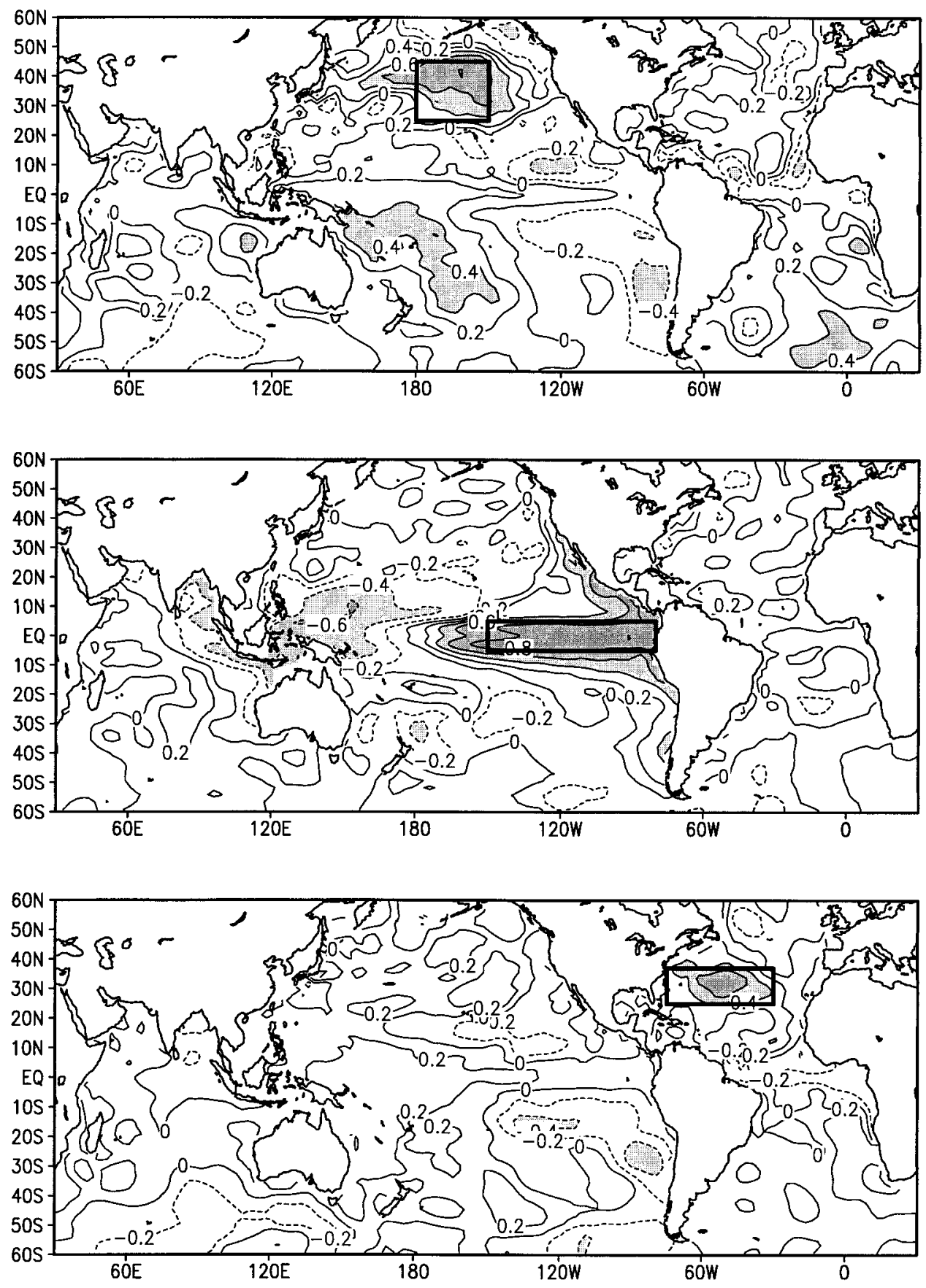

FIG. 11. Correlation of three heat content anomaly time series shown in Fig. 10 with global heat content anomaly. (a) North Pacific, (b) tropical Pacific, and (c) North Atlantic.

opycnal coordinate forecast models may prove helpful.

2) The inability of the forecast model to produce realistic mixed layer salinity. Our lack of knowledge of historical surface salinity limits any estimate of interannual fluctuations of salinity in the mixed layer and contributes to the problems associated with insufficient thermocline water-mass formation. Im- provements in estimate of historical rainfall may help address this problem.

3) The inability of the forecast model to simulate the effects of important narrow topographic features. Our lack of resolution limits the ability of the forecast model to resolve features such as the Strait of Gibraltar, the Windward Islands, or the Florida Straits in the North Atlantic, all of which have pro- 
found effects on the general circulation. Lack of resolution limits mesoscale eddy production and alters the dynamical balances in narrow currents such as the Gulf Stream and the equatorial current systems. On the other hand, increasing resolution will increase production of mesoscale eddies. These eddies must be treated as noise since they are not resolved by the observation set prior to the availability of satellite altimetry.

4) The errors in the Indian Ocean and the Southern Hemisphere generally. The adequacy of the historical subsurface data varies with location. Generally speaking, the temperature of the North Atlantic and major shipping routes of the North Pacific is reasonably well sampled throughout most of the last five decades. Sampling in the tropical Atlantic and Pacific Oceans is intermittent, while the Indian Ocean and the southern oceans are always inadequately sampled. Sampling of overlying atmospheric variables is similarly limited. More salinity observations are also badly needed, as are measurements below $500 \mathrm{~m}$. Upgrades to WOA-94 are expected to help fill in some of these data voids (S. Levitus 1997, personal communication).

Despite these problems the authors feel greatly encouraged by the potential of the analysis for upper-ocean climate studies on interannual to decadal timescales.

Acknowledgments. We are very grateful to a number of people who have given us access to their datasets. Mark Swenson and Zengxi Zhou of the Atlantic Oceanographic Marine Laboratory have provided the monthly averaged surface drifters, and Sydney Levitus and Robert Cheney and their colleagues at the National Oceanographic Data Center/NOAA have provided access to the hydrographic and altimeter data. We have benefited from the datasets collected by principal investigators of the Tropical Ocean Global Atmosphere/World Oceanographic Circulation Experiments. Finally, we want to express our gratitude for support from the Office of Global Programs/NOAA under Grant NA66GP0269 and the National Science Foundation under Grant OCE9416894.

\section{REFERENCES}

Bennett, A. F., 1990: Inverse Methods in Physical Oceanography. Cambridge University Press, $346 \mathrm{pp}$.

Carton, J. A., and B. Huang, 1994: Warm events in the tropical Atlantic. J. Phys. Oceanogr., 24, 888-903.

- G. Chepurin, X. Cao, and B. S. Giese, 2000: A simple ocean data assimilation analysis of the global upper ocean 1950-95. Part I: Method. J. Phys. Oceanogr., 30, 294-309.
Cheney, R. E., L. Miller, and J. Lillibridge, 1994: Topex/Poseidon: The $2 \mathrm{~cm}$ solution. J. Geophys. Res., 99, 24, 555-563.

Chepurin, G. A., and J. A. Carton, 1999: Comparison of retrospective analyses of the global ocean heat content. Dyn. Atmos. Oceans, submitted.

da Silva, A. M., C. C. Young, and S. Levitus, 1994: Atlas of Surface Marine Data 1994, Vol. 1: Algorithms and Procedures. NOAA Atlas NESDIS 6, U.S. Department of Commerce, NOAA, NESDIS, $83 \mathrm{pp}$.

Daley, R., 1991: Atmospheric Data Analysis. Cambridge University Press, $457 \mathrm{pp}$.

Deser, C., M. A. Alexander, and M. S. Timlin, 1996: Upper-ocean thermal variations in the North Pacific during 1970-91. J. Climate, 9, 1840-1855.

Enfield, D. B., and D. A. Meyer, 1997: Tropical Atlantic sea surface temperature variability and its relation to El Niño-Southern Oscillation. J. Geophys. Res., 102, 929-945.

Frankignoul, C., F. Bonjean, and G. Reverdin, 1996: Interannual variability of surface currents in the tropical Pacific during 19871993. J. Geophys. Res., 101, 3629-3647.

Graham, N. E., 1994: Decadal-scale climate variability in the tropical and North Pacific during the 1970s and 1980s: Observations and model results. Climate Dyn., 10, 135-162.

Hsiung, J., R. E. Newell, and T. Houghtby, 1989: The annual cycle of oceanic heat storage and oceanic meridional heat transport. Quart. J. Roy. Meteor. Soc., 115, 1-28.

Hurrell, J. W., and H. van Loon, 1997: Decadal variations in climate associated with the North Atlantic Oscillation. Climatic Change, 36, 301-326.

Ji, M., A. Leetmaa, and J. Derber, 1995: An ocean analysis system for seasonal to interannual climate studies. Mon. Wea. Rev., 123, $460-481$.

Latif, M., and T. Barnett, 1994: Causes of decadal climate variability over the North Pacific and North America. Science, 266, 634637.

Levitus, S., 1990: Interpentadal variability of steric sea level and geopotential thickness of the North Atlantic Ocean, 1970-1974 versus 1955-1959. J. Geophys. Res., 95, 5233-5238.

_ _ and J. Antonov, 1995: Observational evidence of interannual to decadal-scale variability of the subsurface temperature-salinity structure of the world ocean. Climatic Change, 31, 495-514.

—, and —-1997: Climatological and Interannual Variability of Temperature, Heat Storage, and Rate of Heat Storage in the Upper Ocean. NESDIS Atlas Series 16, NOAA, 6 pp.

_ - T. P. Boyer, and J. Antonov, 1994: World Ocean Atlas, 1994. Vol. 5: Interannual Variability of Upper Ocean Thermal Structure, NESDIS Atlas Series, NOAA, $176 \mathrm{pp}$.

Malanotte-Rizzoli, P., 1996: Modern Approaches to Data Assimilation in Ocean Modeling. Elsevier, $455 \mathrm{pp}$.

Miller, A. J., D. R. Cayan, and T. P. Barnett, 1994: The 1976-77 climate shift of the Pacific Ocean. Oceanography, 7, 21-26.

Miller, R. N., and M. Cane, 1996: Tropical data assimilation: Theoretical aspects. Modern Approaches to Data Assimilation in Ocean Modeling, P. Malanotte-Rizzoli, Ed., Elsevier, 207-234.

Mitchum, G., 1994: Comparison of TOPEX sea surface heights and tide gauge sea levels. J. Geophys. Res., 99, 24 541-24 553.

Reynolds, R. W., and T. M. Smith, 1994: Improved global sea surface temperature analysis using optimum interpolation. J. Climate, 7, 929-948.

Trenberth, K. E., and J. W. Hurrell, 1994: Decadal atmosphere-ocean variations in the Pacific. Climate Dyn., 9, 303-319.

Wang, B., 1995: Interdecadal changes in El Niño onset in the last four decades. J. Climate, 8, 267-285.

Wunsch, C., 1996: The Ocean Circulation Inverse Problem. Cambridge University Press, $442 \mathrm{pp}$. 